\title{
Estimación del impacto económico de Xylella fastidiosa en Aragón
}

\author{
Y. Martínez ${ }^{1}$ y A. Palacio-Bielsa2,*
}

1 Universidad de Zaragoza. Departamento de Análisis Económico. Instituto Agroalimentario de Aragón - IA2 (Universidad de Zaragoza-CITA), Gran Vía, 2-4, 50005, Zaragoza, España

2 Centro de Investigación y Tecnología Agroalimentaria de Aragón. Unidad de Sanidad Vegetal. Instituto Agroalimentario de Aragón - IA2 (CITA-Universidad de Zaragoza), Avda. Montañana 930, 50059, Zaragoza, España

\section{Resumen}

La aparición de Xylella fastidiosa en 2017 en la península ibérica ha provocado una preocupación creciente en Comunidades Autónomas como Aragón, con una superficie importante de cultivos sensibles a la bacteria y de gran importancia económica. En este artículo se estima el impacto económico de una potencial infección de $X$. fastidiosa en Aragón bajo dos escenarios: presencia no confirmada (situación actual) y presencia confirmada. El trabajo recopila la información de costes públicos que se están asumiendo en la Comunidad Autónoma como consecuencia de la puesta en marcha de medidas cautelares para impedir la entrada y dispersión de la bacteria, y estima los costes privados y públicos que conllevaría la aparición de $X$. fastidiosa en plantaciones de cultivos leñosos y alfalfa, viveros y encinar trufero. Asimismo, presenta un mapa de riesgo de infección por comarcas agrarias. Los resultados muestran que los costes privados por provincia y cultivo oscilan entre 745 y $5.193 € /$ ha en regadío y entre 136 y 3.407 $€ /$ ha en secano. Los costes totales (públicos y privados) por brote de infección ascienden a $600.000 €$ en caso de afectar a una explotación comercial de leñosos, a lo que habría que añadir $31.958 € /$ ha en caso de que quedara afectado un vivero y entre 500 y $90.000 € /$ ha en caso del encinar trufero.

Palabras clave: Bacteria fitopatógena, valoración económica, costes públicos y privados, medidas cautelares, medidas de erradicación.

\section{Estimation of the economic impact of Xylella fastidiosa in Aragón}

\begin{abstract}
The appearance of Xylella fastidiosa in 2017 in the Iberian Peninsula has caused growing concern in regions such as Aragón, with a large area of crops sensitive to bacteria and of great economic importance. The aim of this paper is to estimate the economic impact of a potential infection of $X$. fastidiosa in Aragón under two scenarios: unconfirmed (current situation) and confirmed presence. The information on private and public costs is collected to evaluate the economic impact of the implementation of preventive measures to avoid the introduction and spread of $X$. fastidiosa in woody crops, alfalfa fields, nurseries and truffle-oaks plantations. Also, a map of potential infection risk by agricultural regions is shown. The results show that private costs per province and crop range between 745 and 5,193 €/ha
\end{abstract}

* Autor para correspondencia: apalaciob@aragon.es

Cita del artículo: Martínez Y, Palacio-Bielsa A (en prensa). Estimación del impacto económico de Xylella fastidiosa en Aragón. ITEA-Información Técnica Económica Agraria. Vol. xx: 1-17. https://doi.org/10.12706/itea.2019.008 
in irrigated land and between 136 and 3,407 €/ha in dry land. The costs per infection outbreak amount to $600,000 €$ in the case of affecting woody crops, to which $31,958 € /$ ha would have to be added if a nursery was affected and between 500 and 90,000 €/ha in case of a truffle-oaks plantation.

Keywords: Phytopathogenic bacteria, economic evaluation, public and private costs, preventive measures, eradication measures.

\section{Introducción}

Xylella fastidiosa (Wells et al., 1997) es una bacteria fitopatógena considerada un organismo de cuarentena en la Unión Europea (Unión Europea, 2019a) Puede afectar al menos a 563 especies (EFSA, 2018a) y producir graves enfermedades en cultivos como la vid, el olivo, los cítricos y los frutales del género Prunus (almendro, melocotonero, nectarino, albaricoquero, cerezo, ciruelo, platerina y paraguayo). También puede afectar a la alfalfa, muchas especies forestales, así como a gran número de árboles y arbustos ornamentales. Se transmite a corta distancia por medio de insectos vectores (hemípteros) que se alimentan de la savia que circula por el xilema (Chatterjee et al., 2008), y a largas distancias a través del movimiento de material vegetal infectado (EFSA, 2018b).

$X$. fastidiosa ha sido recientemente identificada en España. Por sus condiciones climáticas, ciertas zonas de la península ibérica presentan un alto riesgo potencial para la expansión de esta bacteria, puesto que su crecimiento óptimo se produce con temperaturas entre 26 y $28^{\circ} \mathrm{C}$ y está adaptada a inviernos suaves o moderados, propios de muchas zonas del litoral e interior. No obstante, las temperaturas inferiores a $8{ }^{\circ} \mathrm{C}$ o superiores a $34^{\circ} \mathrm{C}$ comprometen su supervivencia en la planta (Feil y Purcell, 2001). Navas-Cortés (2017a) ha definido el mapa de riesgo potencial de infección de $X$. fastidiosa para la península ibérica e Islas Baleares con base a la temperatura mínima invernal. De acuerdo con este mapa, Aragón presenta amplias zonas con riesgo moderado en zonas más próximas al Valle del Ebro.
La primera detección de $X$. fastidiosa en España tuvo lugar en octubre de 2016, en las Islas Baleares. La situación es desalentadora, habiendo detectado hasta la fecha más de 800 casos positivos en las islas de Mallorca, Menorca e lbiza, que afectan a grandes superficies de almendros, olivo y vid, así como a diversas especies de árboles y plantas ornamentales y silvestres (entre ellas, el acebuche). Actualmente la bacteria está ampliamente distribuida y las autoridades exigen la erradicación como norma común con algunas excepciones en las que se permitiría adoptar medidas de contención y que deben autorizarse por parte de la UE (Unión Europea, 2019b). El primer positivo en la península se confirmó en junio de 2017 en la provincia de Alicante (Comunidad Valenciana) y se han confirmado casos positivos en almendro y en algunas especies de plantas silvestres, que delimitan una zona demarcada de más de 87.000 ha, con 22 términos municipales íntegramente afectados y 35 afectados parcialmente (DOGV, 2018a). En abril de $2018 X$. fastidiosa se detectó en un olivo en Villarejo de Salvanés (Comunidad de Madrid). Asimismo, se detectaron 3 plantas ornamentales (Polygala myrtifolia) infectadas en un invernadero de El Ejido (Almería), si bien en este caso se considera que no se trata de un brote sino de un caso aislado.

La aparición de la enfermedad en la península ha provocado una preocupación creciente en la Comunidad Autónoma de Aragón, debido a que muchas de las especies hospedantes de $X$. fastidiosa son cultivos de gran importancia económica y muy extendidos en la región. En julio de 2017, el Gobierno de Aragón publicó un Plan de Contingencia para $X$. fastidiosa, en el que se señalan las 
medidas concretas a adoptar por parte de las autoridades competentes en materia de Sanidad Vegetal [Centro de Sanidad y Certificación Vegetal (CSCV) y Unidad de Salud de los Bosques (USB)]. Los Planes de Contingencia, tanto a nivel nacional como de las distintas Comunidades Autónomas, se revisan periódicamente para adaptarlos a los posibles cambios de la situación de $X$. fastidiosa en Europa y España. En el Plan de Contingencia de Aragón se señalan una serie de acciones que tendrán una repercusión económica importante, tanto en la situación actual en la que el patógeno no está presente como en el caso hipotético de que se detectara la presencia de $X$. fastidiosa.

El objetivo de este trabajo es hacer una estimación de los costes económicos de las medidas establecidas en dicho Plan de Contingencia contra una posible introducción de $X$. fastidiosa en el territorio de Aragón. Para ello, se considerarán dos escenarios relacionados con las acciones concretas previstas: escenario 1 , de prevención o infección no confirmada y escenario 2, de erradicación o infección confirmada. El trabajo se centra en el impacto sobre los cultivos más extendidos en Aragón que podrían verse afectados por la presencia de $X$. fastidiosa: almendro (63.089 ha), olivar para producción de aceite (43.719 ha), viñedo vinificación (33.994 ha), melocotonero (11.187 ha), cerezo (7.135 ha), nectarino (6.524 ha), paraguayo (3.278 ha), albaricoquero (1.951 ha), ciruelo (980 ha) y platerina (340 ha) (DDRS, 2017). También se ha considerado la alfalfa por su importancia económica en la región (101.387 ha), pues está incluido en la lista de vegetales especificados ${ }^{1}$. En el medio forestal, las especies del género Quercus son susceptibles de infección, por lo que también se han considerado en el estudio debido a su estrecha relación con la producción de trufa, de creciente expansión en Aragón. EI área ocupada por las especies de Quercus asciende a 400.913 ha según el Inventario Forestal Nacional, de las cuales 5.271 ha corresponden a plantaciones de encinar trufero (ESYRCE, 2017). Además, se ha evaluado el impacto potencial sobre los viveros comercializadores de cultivos leñosos, que ocupan actualmente 250 ha (DDRS, 2017).

\section{Material y métodos}

La metodología consiste en estimar los costes anuales públicos y privados causados por la bacteria, desglosando cada concepto según el tipo de cultivo y sistema (regadío o secano) cuando las diferencias sean relevantes. Además, se ha calculado la superficie máxima a la que podrían afectar tales costes en los escenarios de presencia confirmada y no confirmada, respectivamente. Por último, se ha realizado una estimación del coste total por brote de infección en el caso de que se confirmase la presencia de $X$. fastidiosa en Aragón.

La mayor dificultad que presenta la estimación adecuada de los costes producidos por $X$. fastidiosa es la imposibilidad de predecir la pauta de infección y expansión asociada a la bacteria. La hipótesis con la que están actuando los responsables del CSCV es la posible presencia de $X$. fastidiosa en parcelas jóvenes, debido a una entrada en el pasado de material procedente de zonas con infecciones confirmadas (Comunidad Valenciana y países con presencia conocida de la bacteria) o una posible entrada futura de material procedente de estas mismas zonas. En principio se considera más improbable que la bacteria pueda llegar a través de insectos vectores, puesto que su capacidad de vuelo está alrededor de los $100 \mathrm{~m}$. Por este motivo los esfuerzos se están concentrando en dos

1. De acuerdo con la Decisión de Ejecución de la Comisión Europea (2015/789/UE), un "vegetal especificado" es una planta sensible a las cepas europeas y no europeas de $X$. fastidiosa, mientras que una "planta hospedadora" es sensible a las cepas europeas de la bacteria. 
frentes: a) el control y análisis exhaustivo del material de los viveros mediante la revisión de la documentación de entradas y salidas de material; y b) la prospección visual y análisis de muestras (tanto con síntomas sospechosos de infección como asintomáticas) en las explotaciones de cultivos leñosos más jóvenes (entre 2 y 4 años).

Dado que actualmente no existe ninguna medida de control efectivo sobre la bacteria y que tampoco es posible establecer una pauta de su expansión espacial, resulta imposible hacer una estimación sobre los costes y beneficios de las medidas cautelares contra $X$. fastidiosa, así como establecer una jerarquía de dichas medidas respecto a su coste-eficacia o coste-eficiencia. Esta dificultad impide establecer posibles escenarios de mayor o menor gravedad en el nivel de infección o afectación espacial, puesto que una vez confirmada la infección, la única medida posible contra su expansión es la destrucción de todo el material vegetal infectado y de los vectores que transmiten la bacteria (Navas-Cortés et al., 2017b).

El cálculo de los costes asociados a $X$. fastidiosa se ha realizado, por tanto, bajo la consideración de estos dos escenarios diferenciados: escenario 1 , de presencia no confirmada y escenario 2 , de presencia confirmada.

En cada uno de estos escenarios se hará una estimación de los costes privados y públicos anuales derivados del Plan de Acción incluido en el Plan de Contingencia, que prevé unas medidas cautelares orientadas a confirmar o desmentir la presencia de la bacteria y evitar su propagación, y unas medidas de erradicación a adoptar en caso de confirmarse la infección. Los costes privados se definen como los costes asumidos por los agricultores o agentes privados en sus parcelas o viveros a consecuencia de la pérdida de producciones y otras medidas de obligada adopción, mientras que los costes públicos incluyen los asumidos por las instituciones públicas como consecuencia de la aplicación del Plan de Acción.
Las acciones concretas incluidas en cada escenario y las fuentes de datos empleadas para la estimación del coste asociado a cada una son las siguientes:

\section{Escenario 1: presencia no confirmada}

En caso de sospecha de existencia de una muestra positiva de $X$. fastidiosa, las medidas cautelares incluyen las siguientes acciones:

- Inspecciones en zonas sospechosas para obtener información (historial de vegetales, detalles de movimiento de material vegetal, localización de parcelas de plantas hospedantes).

- Realización de muestreo de vegetales hospedantes en un radio de $100 \mathrm{~m}$ del lugar sospechoso y análisis de las muestras para confirmar o descartar la presencia de la bacteria.

- Monitorización de la presencia de insectos vectores en parcela/vivero y en las proximidades (100 $\mathrm{m}$ alrededor).

- Eliminación de restos de poda o de material de plantas sospechosas mediante quemado o triturado in situ.

- Eliminación de malas hierbas que puedan actuar como refugio de vectores, en particular Sorghum halepense, Malva spp. y Portulaca oleracea.

Todas estas medidas implican un coste económico que debe asumir la administración encargada del Plan de Acción. En concreto, las inspecciones y muestreos de vegetales, así como la eliminación de malas hierbas y restos de material vegetal se realizan de forma coordinada por el personal técnico del CSCV y de la USB, mientras que los análisis de las muestras (EPPO, 2018) y monitorización de insectos vectores se llevan a cabo en la Unidad de Diagnóstico Fitosanitario del CSCV.

Por tanto, en este escenario solo se incluyen costes públicos y se asume que no se ha con- 
firmado la presencia de la bacteria, si bien es preciso mantener un cierto nivel de prospección y vigilancia que estipula el Plan de Acción con unos parámetros concretos que incluyen la inspección visual, la toma y análisis de muestras y la monitorización de vectores.
La Tabla 1 recoge los cálculos del coste total desglosado por conceptos para cada tipo de actividad, así como la superficie muestreada desde julio a diciembre de 2017. Los costes asociados a las distintas acciones incluyen los siguientes conceptos:

Tabla 1. Coste público anual en el escenario 1.

Table 1. Annual public cost in scenario 1.

Medida

Viveros (250 ha)

Inspección y muestreo

Coste análisis muestras (380 muestras)

Coste personal (3 técnicos)

Subtotal viveros

87.276

90.791

Plantaciones de leñosas (2.800 ha)

Inspección y muestreo

Coste análisis muestras (156 muestras)

Coste personal ( 3 técnicos y 3 agentes de campo)

157.568

Monitorización vectores

Coste del material

78 trampas

1 aspirador

6 mangas

Coste personal (1 agente de campo)

Subtotal leñosas

185.342

Encinar trufero (5.271 ha)

Inspección y muestreo

Coste análisis muestras (10 muestras)

Coste personal (4 técnicos y 4 ayudantes de campo)

210.088

Subtotal encinar trufero

210.181

Coste personal de laboratorio (2 técnicos de laboratorio)

58.184

Coste de divulgación

Coste total

549.998

Fuente: Elaboración propia. 


\section{Costes de inspección y muestreo}

Engloban los costes de inspección, documentación del material vegetal, toma de muestras y análisis de las mismas, así como el coste del personal del CSCV y de la USB asignado a tal fin. Estos costes se han recopilado separadamente para viveros, plantaciones de leñosas y encinar trufero.

El cálculo del coste por muestra analizada en el laboratorio para confirmar o descartar la presencia de $X$. fastidiosa incluye dos conceptos: 1) paso previo de preparación de la muestra vegetal (extracción de ADN); 2) amplificación mediante PCR (Polymerase Chain Reaction) en tiempo real. El coste total por ambos conceptos es de $11,75 €$ por muestra si se incluyen dos protocolos distintos, o bien $9,25 €$ si se incluye un único protocolo (datos facilitados por el (SCV).

Los costes de personal asignado a cada tarea se calculan considerando la tabla de retribuciones anuales para el personal laboral de 2018 del Gobierno de Aragón (2018) incrementadas en un $30 \%$ en concepto de cotizaciones a la Seguridad Social. Los niveles retributivos considerados son nivel 18 para el personal técnico y 13 para los inspectores de campo.

\section{Costes de monitorización de insectos vectores}

Incluyen los costes del material empleado (trampas cromáticas, aspiradores para succión de insectos y mangas entomológicas), y del personal implicado en las tareas. En tanto la presencia de $X$. fastidiosa no sea confirmada no se aplicarán insecticidas, por lo que en este escenario no se considera el coste de los tratamientos contra vectores. Tampoco se contempla la eliminación de restos vegetales, ya que hasta el momento no se ha verificado la presencia de la bacteria. El control de malas hierbas se considera únicamente en el caso de infección confirmada (escenario 2).
Por último, se consideran los costes de divulgación que ha asumido el CSCV, y que incluyen la edición de folletos y hojas informativas, reuniones y foros informativos con profesionales del sector. Todos los datos incluidos en este escenario han sido facilitados por el CSCV y la USB y recopilan la totalidad de los costes asumidos desde julio de 2017, fecha de la puesta en marcha del Plan de Contingencia, hasta diciembre de 2017. Para la estimación del coste anual se duplicará el número de tareas y se considerará el coste de personal anual.

\section{Escenario 2: Presencia confirmada}

En caso de confirmación de la presencia de $X$. fastidiosa, el Plan de Acción prevé la inmediata delimitación de una "zona demarcada" que incluye una "zona infectada" y una "zona tampón". La "zona infectada" abarca, además de las parcelas con material infectado, un radio de $100 \mathrm{~m}$ alrededor de los vegetales que han dado positivo en los análisis de laboratorio. La "zona tampón" incluye una superficie de un radio de $5 \mathrm{~km}$ alrededor de la "zona infectada". Dentro de la "zona infectada" se establecen unas medidas de erradicación de la bacteria, mientras que en la "zona tampón" se mantienen las medidas de inspección descritas como medidas cautelares (escenario 1).

Las medidas de erradicación en la "zona infectada" exigen las siguientes actuaciones:

- Eliminación inmediata e in situ (o lugar cercano designado) de todos los vegetales infectados, de los vegetales sospechosos de estar infectados y de las plantas hospedadoras (estén o no infectadas).

- Aplicación -previa a la eliminación de vegetales- de tratamientos fitosanitarios contra los insectos vectores y contra las plantas que puedan hospedar dichos vectores.

- Muestreo y análisis de los vegetales hospedantes en un radio de $100 \mathrm{~m}$ alrededor de cada vegetal infectado. 
La Tabla 2 muestra el coste público de las medidas a tomar en caso de confirmación de la presencia de $X$. fastidiosa, distinguiendo entre la "zona infectada" y la "zona tampón". Se incluyen los siguientes conceptos:
Coste de tratamientos fitosanitarios contra los insectos vectores

Los tratamientos considerados son los recomendados para el control de Philaenus spumarius, único vector confirmado en Europa

Tabla 2. Medidas a adoptar en el escenario 2 y costes públicos asociados.

Table 2. Measures under scenario 2 and associated public costs.

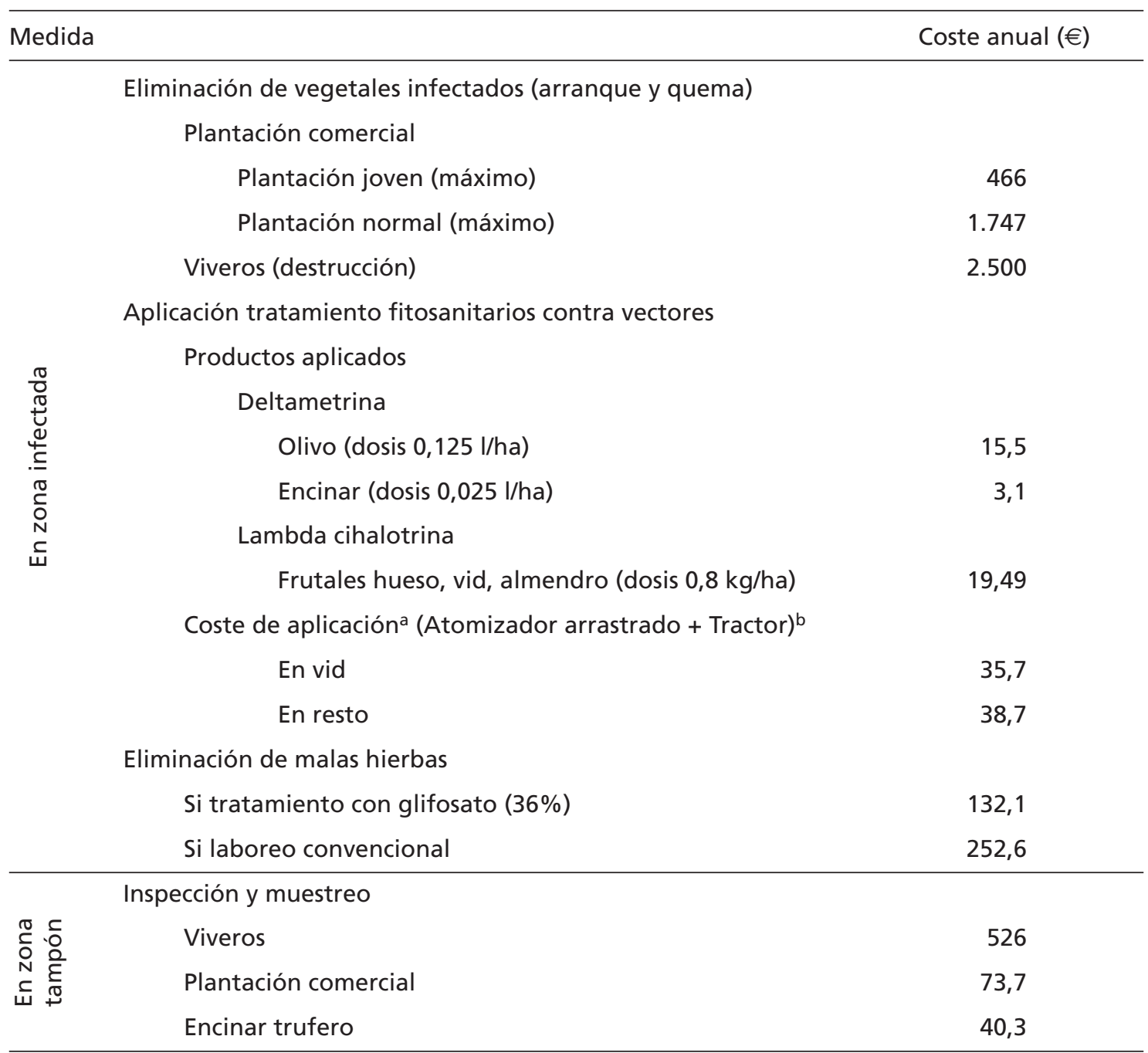

a 1,2 horas/ha en vid; 1,3 horas/ha resto; ${ }^{\text {b } 2 ~ r u e d a s ~ m o t r i c e s ~ y ~} 60 \mathrm{cv}$.

Fuente: Elaboración propia. 
hasta el momento y que está ampliamente distribuido en España y en Aragón. El coste total incluye los productos y su aplicación (maquinaria, combustible y mano de obra), seleccionándose los productos más efectivos y más baratos para cada cultivo, así como las dosis recomendadas en el Registro de Productos Fitosanitarios del Ministerio de Agricultura, Pesca y Alimentación (MAGRAMA, 2018). Para calcular el coste de aplicación se ha empleado la hoja de cálculo para la previsión de costes horarios y anuales de maquinaria agrícola de Barrio (2018). El coste de mano de obra se obtiene asumiendo el número de horas necesarias para la aplicación de fitosanitarios definidas en Fernández-Alcázar (2011) y Mendoza (2015), que son 1,2 horas/ha para la vid y 1,3 horas/ha para el resto de cultivos. El salario diario para el personal encargado de la aplicación es de $52 €$ (MAGRAMA, 2017).

\section{Coste de eliminación de malas hierbas hospedantes}

En este caso se han considerado dos alternativas diferentes en función del tipo de manejo que en el momento de la infección se esté llevando a cabo en la explotación. Si se confirma la infección en una parcela, debe procederse al arranque y destrucción de los árboles, por lo que para eliminar las malas hierbas podría aplicarse un tratamiento herbicida con glifosato como principal producto (sistema de no laboreo), o como alternativa, un sistema de laboreo convencional con cultivador, si se prefiere o sospecha de la existencia de especies de difícil control químico. Los costes considerados aquí son los calculados en el trabajo de Martínez y Pardo (2016) para ambos tipos de gestión de una explotación de frutales e incluyen el coste de aplicación (mano de obra, maquinaria y combustible) y el coste de los herbicidas utilizados en su caso. Dichos costes ascienden a $132,1 € /$ ha si se hace el tratamiento químico habitual de no laboreo y a $252,6 € /$ ha en manejo convencional.

\section{Eliminación de los vegetales infectados}

Implica tanto costes públicos como privados. Los costes públicos por este concepto engloban los trabajos de arranque y destrucción de los frutales de la "zona infectada". Para ese caso, el Gobierno de Aragón (2012) tiene establecido un baremo que fija los importes para compensar el coste que asumiría el agricultor por corte, quemado, destoconado y transporte. El baremo distingue unos importes máximos en función de la edad y estado de producción de la plantación. En este trabajo se distinguen dos posibles situaciones: la de una plantación intensiva normal (más de 20 años, en riego localizado y en estado óptimo), cuyo importe máximo asciende a 1.747 $€ /$ ha, y la de una plantación intensiva joven (hasta 3 ciclos vegetativos, riego localizado y en estado óptimo), con un importe máximo de $466 € / h a$. La elección de estos costes supone, por tanto, una estimación al alza, dado que para plantaciones con características distintas este importe se corrige a la baja. En el caso de los viveros no existe ningún baremo establecido para la compensación por este concepto, por lo que se ha aplicado el fijado en el caso de la Comunidad Valenciana, que asciende a un máximo de $2.500 € /$ ha (DOGV, 2018b).

Los costes privados de la eliminación de vegetales infectados engloban los costes debidos a la pérdida de producciones en las plantaciones de leñosas, en viveros y en explotaciones truferas.

Para el cálculo de estos costes en plantaciones se ha calculado la pérdida de margen bruto por ha para cada cultivo, que afectaría exclusivamente a la superficie en producción. La variable "margen bruto" se define como la diferencia entre los ingresos y los costes directos de producción, maquinaria y mano de obra asalariada. Dicho margen se ha estimado como porcentaje medio sobre los ingresos, calculado a partir de los Estudios de Costes y Rentas de las Explotaciones Agrarias (ECREA, 
2013, 2014 y 2015) que publica anualmente el Ministerio de Agricultura².

En el caso de algunos productos para los que ECREA no calcula márgenes para Aragón, se han tomado los porcentajes calculados para España (ciruelo y olivo en secano). Para todos los productos se emplea el mismo porcentaje en regadío y en secano, excepto en el olivar, para el que existen datos diferenciados.

Estos porcentajes se aplicarán a los ingresos medios estimados, que se calculan a su vez, multiplicando las producciones provinciales medias por los precios provinciales medios. Las producciones provinciales medias se han obtenido a partir de la base datos del Departamento de Desarrollo Rural y Sostenibilidad (DDRS) del Gobierno de Aragón (DDRS, 2017). Dado que, por razones climáticas, las producciones son muy variables de una campaña a otra se ha calculado la media de las producciones obtenidas en las campañas de 2012 a 2016.

En el caso de los precios de los cultivos, se han calculado también medias para cada provincia. Para ello existe la dificultad de que los últimos datos oficiales publicados son los correspondientes a la Encuesta de Rendimientos Provinciales de 2014 (Gobierno de Aragón, 2015). Para poder incluir precios de los años 2015 y 2016, se ha calculado la variación interanual en los precios medios percibidos por los agricultores en España de 2014 a 2015 y 2016 publicados por el MAGRAMA (2017) y posteriormente se ha aplicado dicha variación a los precios de las provincias de Aragón de 2014, obteniendo así los precios provinciales de 2015 y 2016. En el caso particular de la al- falfa, se utiliza el margen bruto estimado por Pardo et al. (2016), que es una media de los años 2010 a 2014.

Para los viveros, los costes privados deben incluir las pérdidas de ingresos provocadas por las medidas asociadas a la detección de $X$. fastidiosa. Si el vivero está localizado en una "zona infectada", deberá destruirse el material producido y se verá obligado a paralizar las ventas de sus plantas, incluso en el caso de no tener material infectado. Para estimar las pérdidas por este concepto se han utilizado los datos de producción total de viveros en Aragón en la campaña 2015-2016 proporcionados por el CSCV. La Tabla 3 incluye el cálculo de los valores de producción estimados de plantones de especies leñosas y forestales. El valor económico de esta producción se estima utilizando el precio por plantón considerado en las últimas estadísticas oficiales publicadas en Aragón (Gobierno de Aragón, 2015). No se recoge el valor de las plantas ornamentales, la pérdida del valor de la inversión inicial, ni considera los costes por destrucción de plantas e imposibilidad de replantación ${ }^{3}$.

Con respecto al caso particular de las explotaciones de encinar trufero, los costes se evalúan considerando la pérdida de valor de producción. La información disponible sobre superficies, producción y valor de la producción es muy escasa y con una gran variabilidad en función de la fuente consultada. Según el MAGRAMA, la superficie es de 5.271 ha para Aragón (ESYRCE, 2017), aunque este dato contrasta con la estimada por Albisu et al. (2016), que indican una superficie entre los 7.500-8.000 ha. Para el cálculo del valor de la producción se utilizan las estimadas por Al-

2. Los estudios ECREA se han utilizado para el cálculo de las indemnizaciones que percibirán los agricultores afectados por $X$. fastidiosa en la Comunidad Valenciana (DOGV, 2018b), que se calculan como el valor presente de los flujos de margen dejados de obtener en toda la vida útil de la plantación.

3. Aunque no se incluyen en los cálculos, la producción en Aragón de plantas ornamentales en maceta asciende a 236.572 unidades. 
Tabla 3. Valor de producción en viveros y coste privado máximo en caso de infección.

Table 3. Production value in nurseries and maximum private costs under infection.

\begin{tabular}{|c|c|c|c|}
\hline Cultivos & Unidades producidas & Valor (€/plantón) & Valor producción $(€)$ \\
\hline Albaricoquero & 139.725 & 2,40 & 335.340 \\
\hline Almendro & 846.134 & 2,80 & 2.369 .175 \\
\hline Cerezo & 155.771 & 2,55 & 397.216 \\
\hline Ciruelo & 147.637 & 2,40 & 354.329 \\
\hline Melocotonero' & 585.849 & 3,00 & 1.757 .547 \\
\hline Olivo & 1.367 .398 & 1,50 & 2.051 .097 \\
\hline Vid (injertos) & 1.035 .430 & 0,53 & 548.778 \\
\hline Total frutales & 4.277 .944 & - & 7.813 .482 \\
\hline Coníferas $^{2}$ & 131.000 & 0,24 & 31.440 \\
\hline Frondosas $^{2}$ & 301.000 & 0,48 & 144.480 \\
\hline Total forestales & 432.000 & - & 175.920 \\
\hline Total & 4.709 .944 & & 7.989 .402 \\
\hline
\end{tabular}

${ }^{1}$ Incluye nectarino, paraguayo y platerina.

${ }^{2}$ Las especies de coníferas más utilizadas en parques y jardines incluyen plátano, castaño, nogal, haya, laurel, roble, sauce y fresno; Las frondosas más utilizadas son abeto, pino, ciprés, cedro, sabina y tejo. Fuente: Elaboración propia.

bisu et al. (2016). Tampoco en este caso se incluye una estimación de la pérdida del valor de la inversión inicial ni por imposibilidad de replantación.

El cálculo del coste de las medidas en la "zona tampón" se hace utilizando los mismos conceptos descritos en el escenario 1 de medidas cautelares (inspección y muestreo de vegetales, control de movimientos de material en viveros y monitorización de vectores).

\section{Resultados y discusión}

\section{Escenario 1: presencia no confirmada}

El coste total final estimado en el escenario 1 asciende a $549.998 €$ (Tabla 1). Para calcu- lar el coste correspondiente a cada tipo de actividad se ha asignado el coste de personal de laboratorio en proporción al número de muestras analizadas en 2017, por lo que dos tercios corresponden a viveros y un tercio a plantaciones comerciales. El coste de divulgación se ha asignado a partes iguales entre las tres actividades. Por tanto, $131.414 €$ (526 $€ / h a)$ corresponden a las medidas adoptadas en viveros, $206.571 €(73,7 € /$ ha) $)$ en plantaciones comerciales y a $212.644 €(40,3 € / \mathrm{ha})$ en explotaciones truferas.

\section{Escenario 2: presencia confirmada}

Los costes privados de este escenario se presentan diferenciando viveros, plantaciones de leñosas, alfalfa y explotaciones de encinar trufero. 
Viveros

El valor total generado por los viveros asciende a 7.989.402 € (Tabla 3), por lo que la pérdida máxima anual estimada en caso de aparición de $X$. fastidiosa ascendería a 31.958 $€ /$ ha si se divide por la superficie actual de viveros (250 ha). Este cálculo recoge únicamente la pérdida anual de ingresos por imposibilidad de venta del material producido.

\section{Plantaciones de leñosas, alfalfa} $y$ encinar trufero

Respecto a las plantaciones de leñosas, la Tabla 4 muestra el cálculo de los ingresos y márgenes medios en Aragón por producto y tipo de riego. Las producciones obtenidas en secano son entre 18 y $83 \%$ inferiores a las de regadío, lo que redunda en una mayor pérdida de márgenes asociada al regadío. En el cultivo de alfalfa las pérdidas asociadas serían de $547 € /$ ha en regadío y $274 € /$ ha en secano (Pardo et al., 2016).

Con relación al encinar trufero, las producciones son muy variables de unas zonas a otras y según la época del año. Albisu et al. (2016) estiman unas producciones mínimas en Aragón de entre 5 y $10 \mathrm{~kg} / \mathrm{ha}$ y un máximo de 100 a $150 \mathrm{~kg} / \mathrm{ha}$. Los precios obtenidos a principio de temporada varían entre 100 y $200 € / \mathrm{kg}$ y al final de temporada entre 400 y $600 € / \mathrm{kg}$. Por consiguiente, las pérdidas de valor de la producción estarían en un rango muy amplio: entre 500 y $90.000 € /$ ha según la época y la producción de la zona concreta que se viera afectada por $X$. fastidiosa.

\section{Estimación del coste por brote}

La estimación del coste total en caso de infección, se presenta en las Tablas 5 y 6. La Tabla 5 muestra el coste público desglosado por tipo de actividad en caso de confirmación de infección de $X$. fastidiosa, diferenciando entre la "zona infectada" y la "zona tampón". El coste público en la zona infectada en plantación de leñosas oscila entre 660,8 y $2.066 € /$ ha, dependiendo del cultivo y tipo de manejo, siendo $648,4 € /$ ha en encinar y $2.500 € /$ ha en viveros.

A partir de esta información puede hacerse una estimación del coste total de la aparición de un brote, bajo la hipótesis de que tanto la "zona infectada" como la "zona tampón" se localizan sobre una explotación de leñosas en producción. En la Tabla 6 se presenta el coste total estimado por brote en los cultivos de regadío. En la "zona infectada" se calcula el coste público considerando una plantación normal, con laboreo convencional y una superficie de 3,14 ha (100 m de radio a partir del brote) a la que afectarían estos costes. El coste privado se ha obtenido asumiendo el margen medio (Tabla 4) para los cultivos en regadío, multiplicado por la superficie de 3,14 ha. Por otro lado, en la "zona tampón" se considera el coste unitario estimado de la Tabla 5, multiplicado por la superficie total de $7.851 \mathrm{ha}$ ( $5 \mathrm{~km}$ de radio a partir del brote).

Los resultados de la Tabla 6 sirven para ilustrar la magnitud relativa de los costes calculados en el trabajo, pues resulta evidente que el coste de las medidas en la "zona tampón" es mucho mayor que el relacionado con la "zona infectada". En todos los casos el coste total por brote está próximo a los $600.000 €$ anuales, tanto en regadío como en secano" ${ }^{4}$. En caso de que dentro de la "zona infectada" hubiera viveros, a la cantidad anterior habría que añadirle un coste privado de $31.938 € /$ ha y un coste público de 2.500 $€ /$ ha. Si el vivero se localiza en la "zona tampón", el coste público sería de $526 € /$ ha.

4. Aunque no se muestran aquí, los cálculos para los cultivos de secano están entre 585.000 y $595.000 €$. 


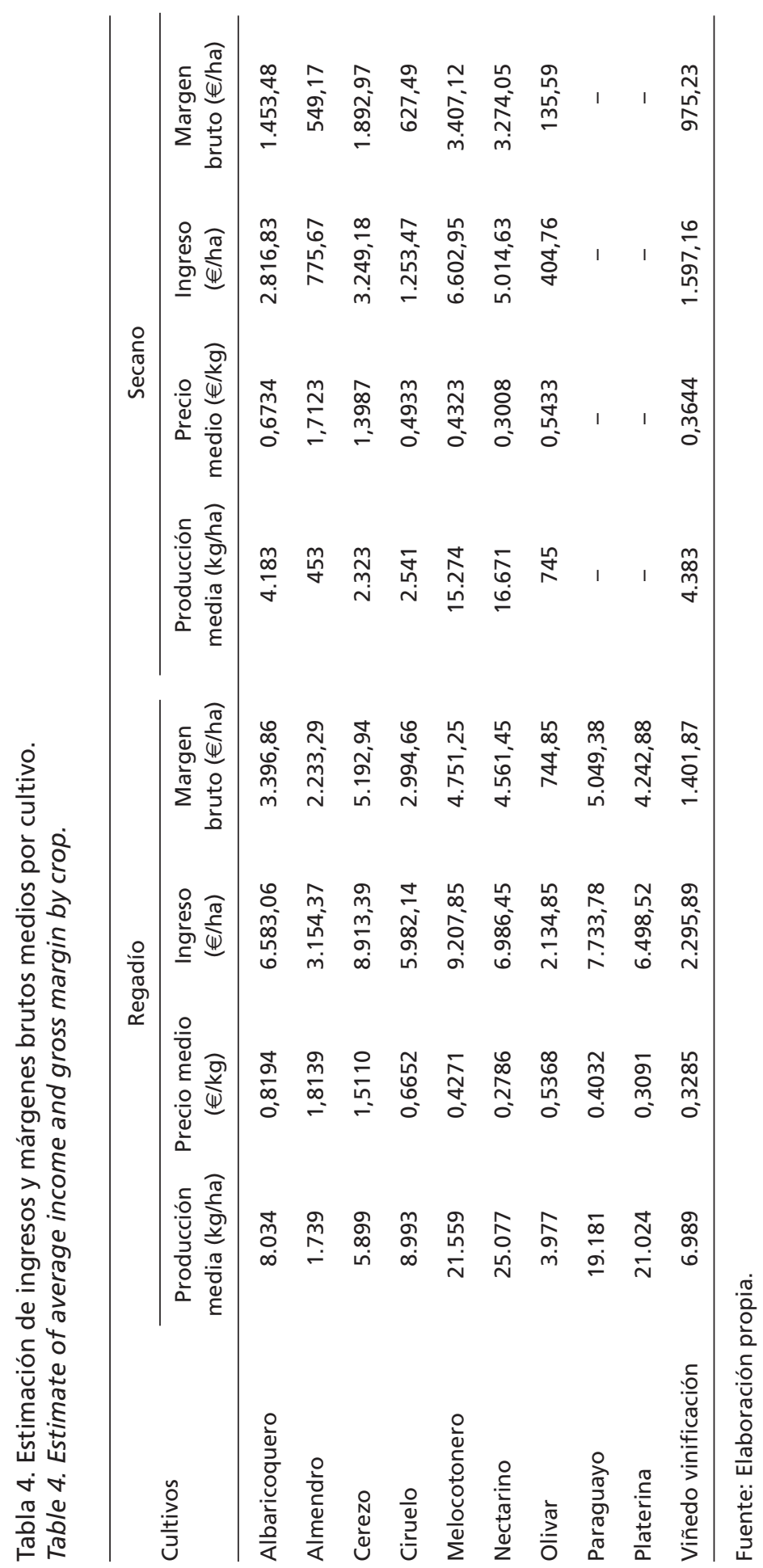


Tabla 5. Costes públicos por tipo de explotación y cultivo.

Table 5. Public costs by type of farm and crop.

\begin{tabular}{|c|c|c|c|c|c|c|}
\hline \multirow{4}{*}{ Cultivos } & \multicolumn{6}{|c|}{ Costes públicos (€/ha) } \\
\hline & \multicolumn{5}{|c|}{ Zona infectada } & \multirow{3}{*}{$\begin{array}{c}\text { Zona tampór } \\
\\
\text { Inspección y } \\
\text { muestreo }\end{array}$} \\
\hline & \multicolumn{2}{|c|}{$\begin{array}{l}\text { Destrucción } \\
\text { vegetales }\end{array}$} & \multirow{2}{*}{$\begin{array}{l}\text { Insectos } \\
\text { vectores }\end{array}$} & \multicolumn{2}{|c|}{ Malas hierbas } & \\
\hline & $J$ & $\mathrm{~N}$ & & NL & LC & \\
\hline Albaricoquero & 466 & 1.747 & 66,6 & 132,1 & 252,3 & 73,7 \\
\hline Almendro & 466 & 1.747 & 66,6 & 132,1 & 252,3 & 73,7 \\
\hline Cerezo & 466 & 1.747 & 66,6 & 132,1 & 252,3 & 73,7 \\
\hline Ciruelo & 466 & 1.747 & 66,6 & 132,1 & 252,3 & 73,7 \\
\hline Melocotonero & 466 & 1.747 & 66,6 & 132,1 & 252,3 & 73,7 \\
\hline Nectarino & 466 & 1.747 & 66,6 & 132,1 & 252,3 & 73,7 \\
\hline Olivar & 466 & 1.747 & 62,7 & 132,1 & 252,3 & 73,7 \\
\hline Paraguayo & 466 & 1.747 & 66,6 & 132,1 & 252,3 & 73,7 \\
\hline Platerina & 466 & 1.747 & 66,6 & 132,1 & 252,3 & 73,7 \\
\hline Viñedo (vinificación) & 466 & 1.747 & 63,0 & 132,1 & 252,3 & 73,7 \\
\hline Explotación trufera & 466 & 1.747 & 50,3 & 132,1 & 252,3 & 40,3 \\
\hline Viveros & & & - & - & - & 526 \\
\hline
\end{tabular}

J: plantación joven; N: plantación normal; NL: no laboreo; LC: laboreo convencional.

Fuente: Elaboración propia.

Tabla 6. Coste estimado por brote de infección para los cultivos en regadío (en €).

Table 6. Estimated costs per infected point for irrigated crops (in €).

\begin{tabular}{lcccc}
\hline \multirow{2}{*}{ Cultivos } & \multicolumn{2}{c}{ Zona infectada } & Zona tampón & $\begin{array}{c}\text { Coste total } \\
\text { por brote }\end{array}$ \\
\cline { 2 - 3 } & Coste público & Coste privado & & 578.619 \\
Albaricoquero & $6.474,6$ & $10.666,1$ & 595.760 \\
Almendro & $6.486,8$ & $7.012,5$ & 578.619 & 592.118 \\
Cerezo & $6.486,8$ & $16.305,8$ & 578.619 & 601.412 \\
Ciruelo & $6.486,8$ & $9.403,2$ & 578.619 & 594.509 \\
Melocotonero & $6.486,8$ & $14.918,9$ & 578.619 & 600.025 \\
Nectarino & $6.486,8$ & $14.322,9$ & 578.619 & 599.429 \\
Paraguayo & $6.486,8$ & $15.855,1$ & 578.619 & 600.961 \\
Platerina & $6.486,8$ & $13.322,6$ & 578.619 & 598.428 \\
Olivar & $6.474,6$ & $2.338,8$ & 578.619 & 587.432 \\
Viñedo (vinificación) & $6.475,5$ & $4.401,9$ & 578.619 & 589.496 \\
\hline
\end{tabular}

Fuente: Elaboración propia. 
Igualmente, si en la "zona infectada" se localizan explotaciones truferas, el coste público máximo sería de $2.050 € /$ ha y el privado entre 500 y $90.000 € /$ ha, mientras que si la explotación se localiza en la "zona tampón" el coste público sería de $40,3 € /$ ha.

Estos resultados se han obtenido bajo la hipótesis de que se mantenga el nivel de muestreo actual (268 muestras en 1.650 ha). Sin embargo, la experiencia de la Comunidad Valenciana muestra que este ritmo de muestreo se incrementa notablemente en la zona delimitada (953 muestras en $653 \mathrm{ha}$ ) (Dalmau, 2017). Esto sugiere que la intensidad de muestreo tendría que multiplicarse casi por 9, por lo que la estimación de costes públicos asociados a la aparición de un brote debe considerarse con cautela, sobre todo en lo referente a los costes de personal asociados a la recogida y análisis de muestras. Además, en el caso de que existieran varios brotes de infección y se solaparan las zonas delimitadas, los costes por brote serían inferiores al calculado, por lo que el coste estimado aquí puede considerarse un máximo.

\section{Riesgo potencial asociado al clima en Aragón}

Una cuestión relevante con relación al impacto de $X$. fastidiosa en Aragón es el riesgo de infección asociado a las condiciones climáticas. La Figura 1 presenta las comarcas aragonesas con el riesgo potencial asociado. Las comarcas de Caspe, las zonas de ribera de las comarcas del Bajo Aragón, Zaragoza, Ejea de los Caballeros y Borja, y algunas áreas del Bajo Cinca serían las de mayor riesgo de infección (riesgo moderado). Estas comarcas suponen una superficie total de cultivos leñosos de 97.670 ha, especialmente almendro y olivo en secano (31.616 ha y 25.439 ha, respectivamente). También hay superficies considerables de viñedo en Borja (6.305 ha) y de frutales de hueso en Caspe (4.543 ha) y Bajo Cinca (9.583 ha). Las comarcas con riesgo ocasional serían la Hoya de Huesca, Monegros, Somontano, La Litera, Bajo Cinca y La Almunia, con una superficie total de 57.376 ha de cultivos leñosos. En estas zonas son relevantes los cultivos de viñedo (18.983 ha), frutales de hueso (16.691 ha) y olivar (8.850 ha). Por último, las comarcas de Jacetania, Ribagorza y Sobrarbe, Daroca y gran parte de Calatayud, y Sierra de Albarracín, Jiloca, Serranía de Montalbán, Maestrazgo y amplias áreas de la Hoya de Teruel tendrían un riesgo nulo.

Esta distribución de riesgo potencial y también el daño asociado a cada cultivo podrían considerarse criterios para intensificar los muestreos en las comarcas del valle del Ebro (Caspe, Bajo Cinca, Bajo Aragón, Zaragoza, Borja y Ejea de los Caballeros.).

\section{Conclusiones}

La posible aparición de $X$. fastidiosa plantea importantes retos debido a la dificultad para aislar la infección y evitar su propagación. Dado que hasta el momento no existe un método de control eficaz, la rápida detección de la bacteria se considera básica para evitar los graves efectos de su expansión. La recopilación de los costes derivados de las medidas cautelares incluidas en el Plan de Contingencia de Aragón de 2017 permite estimar los costes anuales públicos que actualmente están asumiendo las instituciones competentes en materia de Sanidad Vegetal y confirman la importancia de una rápida detección de la bacteria para evitar los costes económicos derivados de su expansión. Este cálculo permite además hacer una previsión de los costes que deberían asumirse en la "zona tampón" en caso de infección.

La estimación de costes privados en la "zona infectada" por tipo de actividad es importante para el cálculo de las posibles indemnizaciones que compensarían las pérdidas pro- 


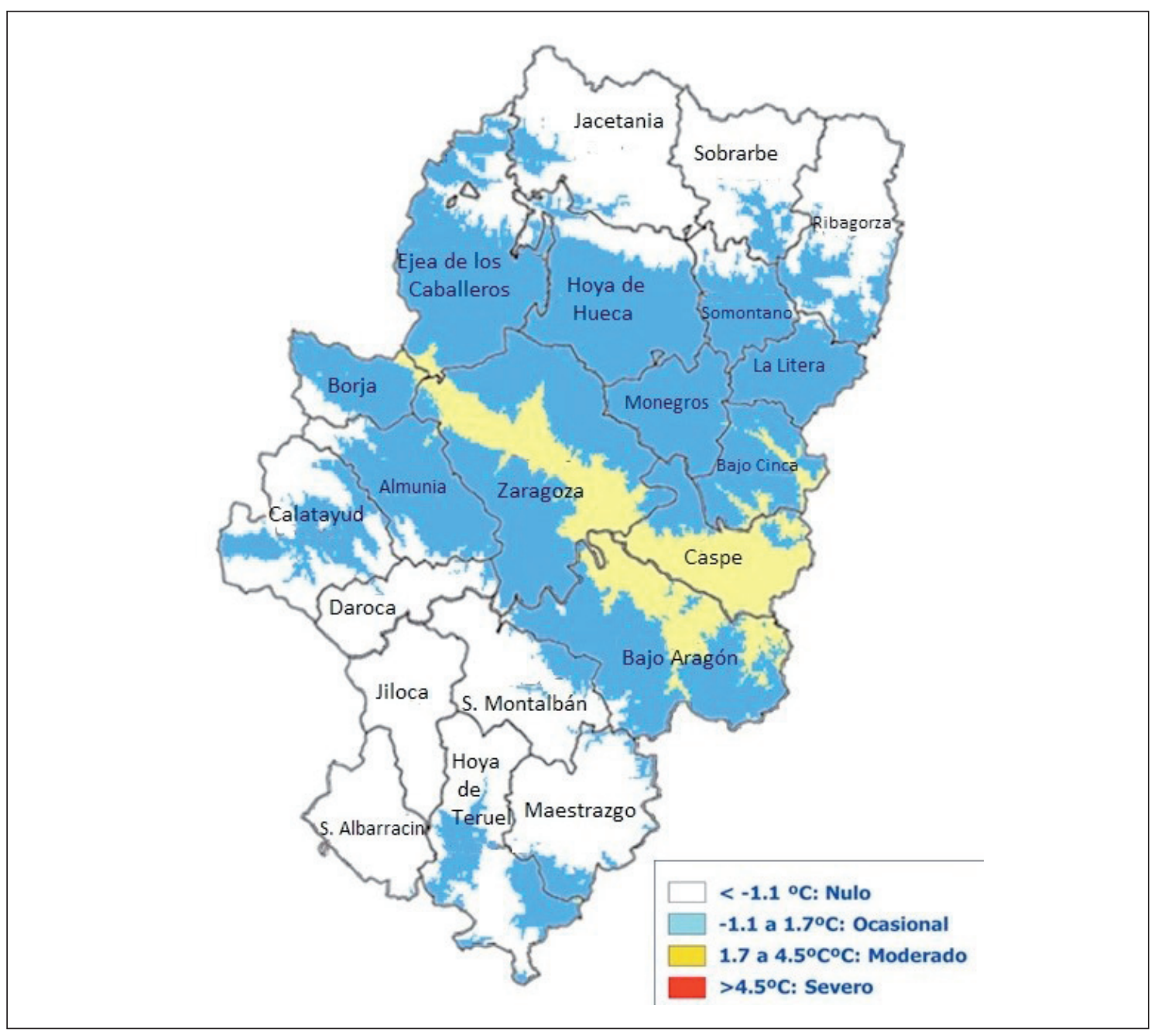

Fuente: Elaboración propia de JA Navas-Cortés, Instituto de Agricultura Sostenible (IAS), CSIC (2018). Figura 1. Mapa de riesgo potencial para la Comunidad Autónoma de Aragón.

Figure 1. Map of potential risk for Aragón.

vocadas por $X$. fastidiosa. Además, la identificación de las zonas de riesgo potencial puede servir como criterio para intensificar la inspección y los muestreos en las áreas y cultivos con mayores pérdidas potenciales y peligro de infección.

Los resultados de este trabajo pueden ser útiles en la toma de decisiones por parte de las autoridades competentes en materia de Sanidad Vegetal, no solo a nivel local sino también a nivel global, porque permiten hacer una previsión de los costes públicos y privados por tipo de actividad que deberían asumirse en caso de infección y anticipar el tipo y costes de las medidas necesarias para la prevención y erradicación de la infección. 


\section{Agradecimientos}

Este trabajo se ha llevado a cabo en el marco del proyecto E-RTA2017-00004-C06-00 de la Agencia Estatal de Investigación y el Instituto Nacional de Investigaciones Agrarias, y del Proyecto 2018/0344 financiado por el Gobierno de Aragón a través del Centro de Sanidad y Certificación Vegetal de Aragón (CSCV). Agradecemos a Juan Antonio Navas-Cortés la elaboración del mapa de riesgo climático potencial para el establecimiento de Xylella fastidiosa en la C. A. de Aragón. Asímismo, agradecemos la información facilitada por Luis Mariano Roldán (Gobierno de Aragón) y por Pedro Mingote, María Teresa Sanz, Ana María Aguado y Emilio Betrán del CSCV.

\section{Referencias bibliográficas}

Albisu LM, Herrando E, Meza L, Barriuso J (2016). La trufa negra en España: organización de sus mercados. Documento de trabajo. Repositorio CITAREA. Disponible en: http://hdl.handle.net/ 10532/3567 (Consultado: 30 octubre 2018).

Barrio JJ (2018). Hoja de cálculo para la previsión de costes horarios y anuales de máquinas agrícolas. Departamento de Agricultura y Alimentación, Gobierno de La Rioja. Disponible en https://www.unirioja.es/dptos/daa/docencia/1011013costes.xls (Consultado: 20 agosto 2018).

Chatterjee S, Almeida RPP, Lindow S (2008). Living in two worlds: The plant and insect lifestyles of Xylella fastidiosa. Annual Review of Phytopathology 46: 243-271. https://doi.org/10.1146/annurev.phyto.45.062806.094342

Dalmau V (2017). Situación de Xylella fastidiosa en la Comunidad Valenciana. Presentación en el III Foro de Sanidad Vegetal, 21 de noviembre, Zaragoza, España.

DDRS (2017). Encuestas de cultivos leñosos, 2013 a 2016. Unidad de Estadísticas, Departamento de Desarrollo Rural y Sostenibilidad, Gobierno de Aragón.
DOGV (2018a). RESOLUCIÓN de 16 de julio de 2018 del director general de Agricultura, Ganadería y Pesca, por la cual se declara la octava actualización de la situación de la plaga Xylella fastidiosa (Wells et al.) en el territorio de la Comunitat Valenciana y se adoptan medidas fitosanitarias urgentes de erradicación y control para evitar su propagación. Diari Oficial de la Generalitat Valenciana, núm. 8342, pp. 30691-30696.

DOGV (2018b). ORDEN 6/018, de 5 de febrero, de la Conselleria de Agricultura, Medio Ambiente, Cambio Climático y Desarrollo Rural, por la que se aprueban las bases reguladoras de las ayudas indemnizatorias para la erradicación y el control de Xylella fastidiosa. Diari Oficial de la Generalitat Valenciana, núm. 8236, pp. 7243-7255.

ECREA $(2013,2014,2015)$. Estudios de costes de explotaciones agrícolas. Resultados Técnicoeconómicos. Ministerio de Agricultura, Alimentación y Medio Ambiente, Gobierno de España.

EFSA (2018a). Update of the Xylella spp. host plant database. EFSA Journal 16(9):5408. https://doi.org/ 10.2903/j.efsa.2018.5408.

EFSA (2018b). Updated pest categorisation of Xylella fastidiosa. EFSA Journal 16(7): 5357. https://doi.org/10.2903/j.efsa.2018.5357.

EPPO (2018). PM 7/24 (3) Xylella fastidiosa. EPPO Bulletin 48: 175-218. https://doi.org/10.1111/ epp. 12469

ESYRCE (2017). Encuesta sobre Superficie y Rendimientos de cultivos. Ministerio de Agricultura, Alimentación y Medio Ambiente, Gobierno de España.

Feil H, Purcell AH (2001). Temperature-dependent growth and survival of Xylella fastidiosa in vitro and in potted grapevines. Plant Disease 85: 1230-1234. https://doi.org/10.1094/PDIS.2001. 85.12 .1230

Fernández-Alcázar JI (2011). Costes de cultivo en viñedo. Cuaderno de campo 46: 4-13.

Gobierno de Aragón (2012). Valoración de los trabajos de arranque y destrucción de plantaciones de frutales. Departamento de Agricultura, Ganadería y Medio Ambiente, Gobierno de Aragón. 
Gobierno de Aragón (2015). Anuario estadístico agrario de Aragón 2013-2014. Servicio de Estudios, Análisis e Información del Departamento de Desarrollo Rural y Sostenibilidad, Gobierno de Aragón.

Gobierno de Aragón (2018). Tabla de retribuciones anuales de funcionarios 2018. Dirección General de Presupuestos, Financiación y Tesorería, Gobierno de Aragón.

MAGRAMA (2017). Índices de precios y precios percibidos por los agricultores. Ministerio de Agricultura, Pesca y Alimentación, Gobierno de España.

MAGRAMA (2018). Registro de Productos Fitosanitarios. Ministerio de Agricultura, Alimentación y Medio Ambiente, Gobierno de España.

Martínez Y, Pardo G (2016). Cultivos leñosos en Aragón: evaluación económica de una eventual prohibición del glifosato. Economía Agraria y Recursos Naturales 16: 143-150. https://doi.org/ 10.7201/earn.2016.02.06

Mendoza S (2015). Costes de cultivo en pera de Conferencia. Cuaderno de Campo 55: 40-45.

Navas-Cortés JA, Montes Borrego M, Landa BB (2017a). Epidemiología. En: Enfermedades causadas por la bacteria Xylella fastidiosa (Eds. Landa BB, Marco-Noales E, López MM), pp. 6172. Cajamar Caja Rural.

Navas-Cortés JA, Montes Borrego M, Landa BB (2017b). Métodos de control. En: Enfermedades causadas por la bacteria Xylella fastidiosa (Eds.
Landa BB, Marco-Noales E, López MM), pp. 135-148. Cajamar Caja Rural.

Pardo G, Cirujeda A, Martínez Y (2016). Evaluación del impacto económico de una especie invasora en el regadío de Aragón: el teosinte. Revista Española de Estudios Agrosociales y Pesqueros 245: 67-96.

Unión Europea (2019a). Directiva 2000/29/CE del Consejo, de 8 de mayo de 2000, relativa a las medidas de protección contra la introducción en la Comunidad de organismos nocivos para los vegetales o productos vegetales y contra su propagación en el interior de la Comunidad, y modificaciones. Disponible en: https://eur-lex.europa.eu/legal-content/ES/ALL/?uri=CELEX\% 3A32000L0029 (Consultado: 02 abril 2019).

Unión Europea (2019b). Decisión de Ejecución (UE) 2015/789 de la Comisión, de 18 de mayo de 2015, sobre medidas para evitar la introducción y propagación dentro de la Unión de Xylella fastidiosa (Wells et al.), y modificaciones. Disponible en: https://eur-lex.europa.eu/legal-content/ES/TXT/?uri=CELEX\%3A32015D0789 (Consultado: 02 abril 2019).

Wells JM, Raju BC, Hung HY, Weisburg WG, Mandelco-Paul L, Brenner DJ (1987). Xylella fastidiosa gen. nov., sp. nov.: Gram-negative, xylem-limited, fastidious plant bacteria related to Xanthomonas spp. International Journal of Systematic Bacteriology 37: 136-143. https://doi.org/10. 1099/00207713-37-2-136

(Aceptado para publicación el 3 de abril de 2019) 